\title{
Development of Controlled-Release Matrix Tablet of Risperidone: Influence of Methocel@- and Ethocel®-Based Novel Polymeric Blend on In Vitro Drug Release and Bioavailability
}

\author{
Amir Badshah, ${ }^{1,4}$ Fazal Subhan, ${ }^{1}$ Khalid Rauf, ${ }^{1}$ Nadeem Irfan Bukhari, ${ }^{2}$ Kifayatullah Shah, ${ }^{3}$ Samiullah Khan, ${ }^{1}$ \\ Zia Ahmed, ${ }^{1}$ and Ihsanullah Khan ${ }^{1}$
}

Received 11 October 2010; accepted 4 April 2011; published online 15 April 2011

\begin{abstract}
Controlled-release (CR) matrix tablet of $4 \mathrm{mg}$ risperidone was developed using flow bound dry granulation-slugging method to improve its safety profile and compliance. Model formulations F1, F2, and F3, consisting of distinct blends of Methocel ${ }^{\circledR}$ K100 LV-CR and Ethocel ${ }^{\circledR}$ standard 7FP premium, were slugged. Each batch of granules $(250-1,000 \mu \mathrm{m})$, obtained by crushing the slugs, was divided into three portions after lubrication and then compressed to 9-, 12-, and 15-kg hard tablets. In vitro drug release studies were carried out in $0.1 \mathrm{~N} \mathrm{HCl}(\mathrm{pH} 1.2)$ and phosphate buffer ( $\mathrm{pH}$ 6.8) using a paddle dissolution apparatus run at $50 \mathrm{rpm}$. The CR test tablet, containing $30 \%$ Methocel ${ }^{\circledR}$ and $60 \%$ Ethocel ${ }^{\circledR}$ (F3) with 12-kg hardness, exhibited $\mathrm{pH}$-independent zero-order release kinetics for $24 \mathrm{~h}$. The drug release rate was inversely proportional to the content of Ethocel®, while the gel layer formed of Methocel ${ }^{\circledR}$ helped in maintaining the integrity of the matrix. Changes in the hardness of tablet did not affect the release kinetics. The tablets were reproducible and stable for 6 months at $40 \pm 2{ }^{\circ} \mathrm{C} / 75 \pm 5 \%$ relative humidity. Risperidone and its active metabolite, 9-hydroxyrisperidone, present in the pooled rabbit's serum, were analyzed with HPLC-UV at $\lambda_{\max } 280 \mathrm{~nm}$. The CR test tablet exhibited bioequivalence to reference conventional tablet in addition to the significantly $(p<0.05)$ optimized peak concentration, $C_{\max }$, and extended peak time, $T_{\max }$, of the active moiety. There was a good association between drug absorption in vivo and drug release in vitro $\left(R^{2}=0.7293\right)$. The successfully developed CR test tablet may be used for better therapeutic outcomes of risperidone.
\end{abstract}

KEY WORDS: controlled release; dry granulation slugging method; risperidone.

\section{INTRODUCTION}

Risperidone, a water-insoluble second-generation antipsychotic drug, is widely used in the clinical management of schizophrenia, bipolar disorder, and irritability in children. 9-Hydroxyrisperidone, a major metabolite of risperidone, was pharmacologically as much potent as the parent compound. The serum concentration of the active moiety is thus the sum of serum concentrations of risperidone and 9-hydroxyrisperidone $(1,2)$.

Noncompliance to antipsychotic drugs has been a major problem since long (3). Noncompliant psychiatric patients suffered an almost double re-hospitalization from relapse, resulting in poor quality of life and increased economic burden (4). Noncompliance to antipsychotic drugs was mainly caused by their side effects (5), including dose-dependent cardiac arrest deaths (6), extrapyramidal side effects, dry

\footnotetext{
${ }^{1}$ Department of Pharmacy, University of Peshawar, Peshawar 25120, Khyber Pakhtoonkhwa, Pakistan.

${ }^{2}$ University College of Pharmacy, Punjab University, Punjab, Pakistan.

${ }^{3}$ Faculty of Pharmacy, Gomal University, D.I.Khan, Khyber Pakhtoonkhwa, Pakistan.

${ }^{4}$ To whom correspondence should be addressed. (e-mail: amir badshah@upesh.edu.pk)
}

mouth, constipation, difficulty in urinating, and loss of accommodation (7). There was a strong association between plasma levels of risperidone and its adverse effects $(8,9)$.

The combined peak concentration $\left(C_{\max }\right)$ of risperidone and its active metabolite, 9-hydroxyrisperidone, was reported as $30 \mathrm{ng} / \mathrm{mL}$ for once-daily 4-mg tablets (10) and $50 \mathrm{ng} / \mathrm{mL}$ for once-daily 6-mg tablets (11), while their combined elimination half-life was approximately $20 \mathrm{~h}$ both in poor and extensive metabolizers (12). A group of investigators (13) suggested 20-60 ng/mL as the optimal concentration of the active moiety for therapeutic activity. Another group of researchers observed $74 \mathrm{ng} / \mathrm{mL}$ active moiety as the threshold limit for causing extrapyramidal side effects (14).

Novel formulations of some antipsychotic drugs have become popular because of convenience in dosage, reduced side effects, and improved efficacy (15). Better therapeutic outcomes were exhibited by the OROS-based extended-release tablet of 9-hydroxyrisperidone (an active metabolite of risperidone) commercially known as Paliperidone, Invega ${ }^{\circledR}$ (16). Similar results have been exhibited by the oral monolithic matrix tablets of carbamazepine (17). A therapeutically favorable drug release profile was shown by the lipid matrices of olanzapine (18).

Matrix tablets meant for oral route are popular because of the simplicity in manufacture, ease and safety in use, and 
cost effectiveness. Hydroxypropyl methylcellulose (HPMC, hydrophilic) has been a popular release-retarding polymer in simple matrix tablets $(19,20)$ and floating gastro-retentive tablets (21,22). Fine particle ethyl cellulose (FPEC) was successfully used in the formulation of extended-release tablets of some non-ionizable drugs (23). Blending of HPMC with other polymers (e.g., ethyl cellulose) has been recommended for the alteration of its functionalities (24). Blends of HPMC with FPEC have shown promising results in our previously published investigation (25).

No study has been reported so far regarding the preparation of risperidone controlled-release matrix tablets. Blends of Methocel ${ }^{\circledR}$ K100 LV-CR and Ethocel ${ }^{\circledR}$ standard 7FP premium, novel versions of HPMC and ethyl cellulose respectively, were employed in the present study to prepare the controlled-release matrix tablets of risperidone. The study also attempted to assess the impact of the novel blend on drug release kinetics and bioavailability.

\section{MATERIALS AND METHODS}

Risperidone (Jubilant Organosys Science Active Ltd., India) was provided by Bryon Pharma, Khyber Pakhtoonkhwa, Pakistan, as a gift sample, and 9-hydroxyrisperidone was purchased from TLC PharmaChem, Canada. Methocel ${ }^{\circledR}$ K100LV-CR and Ethocel ${ }^{\circledR}$ Standard 7FP Premium were gratefully provided as gift samples by Colorcon Asia Ltd., India. Conventional Risperdal ${ }^{\circledR}$ tablets (batch no. 6914 dated May, 2007; Johnson and Johnson (Pvt.) Ltd., Pakistan) of 4-mg risperidone strength were used as reference during in vivo studies. HPLC grade acetonitrile and methanol (Merck, Germany) were purchased from the authorized dealer in the local market. Other chemicals used were of analytical grade.

\section{Preparation of Tablets}

Model formulations F1, F2, and F3 were prepared by blending Methocel® K100 LV-CR (M) and Ethocel® standard 7FP premium (E) in three different proportions. The polymeric blends constituted $90 \%$ portion of formulations $\mathrm{F} 1(60 \% \mathrm{M}$ and $30 \% \mathrm{E}), \mathrm{F} 2(45 \% \mathrm{M}$ and $45 \% \mathrm{E})$, and $\mathrm{F} 3(30 \% \mathrm{M}$ and $60 \% \mathrm{E})$. The polymeric blends were thoroughly mixed with preset fixed amounts of risperidone $(2 \%)$, lactose $(6 \%)$, colloidal silicon dioxide (Aerosil®, $0.5 \%)$, and magnesium stearate $(0.5 \%)$ in a polybag by a geometric dilution method. The powder mixture, thus prepared for a batch of 600 tablets, was initially passed through sieve \#40 and then compressed into slugs with a manually run Tablet Press ZP-17, Shanghai, China, using 17-mm flat-faced tooling. The slugs were crushed first in a pestle and mortar and then in an oscillating granulator (fitted with 20 mesh screen) for sizing the granules $(\geq 200 \mu \mathrm{m}$ to $\leq 1 \mathrm{~mm})$. Aerosil ${ }^{\circledR}(0.5 \%)$ and magnesium stearate $(0.5 \%)$ were mixed well with the pre-sized granules in a polybag. The material thus prepared was divided into three portions and then compressed suitably to alter into tablets of 9-, 12-, and $15-\mathrm{kg}$ hardness with the Tablet Press ZP-17, equipped with $8.00 \times 3.50$-mm tetragonal tooling. Each tablet, containing $4 \mathrm{mg}$ risperidone, weighed $200 \mathrm{mg}$

\section{Physicochemical Evaluation of Powder Mixture, Granules, and Tablets}

The powder mixture and granules thus prepared were evaluated for flow and compressibility characteristics. The angle of repose (AR) of the powder mixture and granules was determined using a fixed funnel, while the compressibility index $(\mathrm{CI})$, and Hausner ratio (HR) were determined with a 100-mL cylinder in accordance with Monograph $\#<1174>$, United States Pharmacopoeia XXX (USP XXX). The granules were assayed for risperidone content with a UVVisible spectrophotometer (Shimadzu, Japan, model 1700) set at $\lambda_{\max }=280 \mathrm{~nm}$ using methanol as the extraction solvent. The friability of the tablets was determined with a friability tester (FB 994, Curio, Pakistan), while the hardness and physical dimensions of the tablets were determined with a hardness plus dimensions tester (CHT 901, Curio). Weight variation was determined as given in Monograph \#<905>, USP XXX. To determine content uniformity, ten tablets were individually crushed, extracting each one with $100 \mathrm{~mL}$ methanol for assay of risperidone, as mentioned above.

Drug release studies were conducted in $900 \mathrm{~mL}$ of $0.1 \mathrm{~N}$ $\mathrm{HCl}(\mathrm{pH}$ 1.2) and $900 \mathrm{~mL}$ of phosphate buffer (pH 6.8) kept at thermostatically controlled temperatures of $37 \pm 0.5^{\circ} \mathrm{C}$ using a type II paddle dissolution apparatus (Erweka, Germany) run at $50 \mathrm{rpm}$. The samples withdrawn were replaced with similar dissolution media. Percent drug release after 1, 2, 4, 6, $8,10,12,16$, and $24 \mathrm{~h}$ was determined with the UV-Visible spectrophotometer at $\lambda_{\max }=280 \mathrm{~nm}$.

The drug release data were fitted to the usual kinetic models, including zero-order, first-order, Higuchi's square root of time, and Hixon and Crowell's cube root of time to determine the release rate $(K)$ and coefficient of determination $\left(R^{2}\right)$. Korsemeyer-Peppas's equation was applied to determine the linearity of the drug release curves (coefficient of determination, $R^{2}$ ) and release exponent $(n)$ with the following equation (26):

$$
\text { Korsemeyer - Peppas's equation, } Q_{t} / Q_{\infty}=k t^{n}
$$

where $Q_{t}$ is the percent drug release at time $t ; Q_{\infty}$ the percent drug release after infinite time, usually taken as $100 ; Q_{t} / Q_{\infty}$ is the fraction of drug released at time $t$; and $k$ in the Korsemeyer's model is a release constant incorporating the structural and geometric characteristics of the system; $n$ is the release exponent, indicative of the drug release mechanism.

Release profiles of the 9-, 12-, and 15-kg hard tablets of the selected formulation F3, determined in dissolution media of $0.1 \mathrm{~N} \mathrm{HCl}$ ( $\mathrm{pH} \mathrm{1.2)} \mathrm{and} \mathrm{phosphate} \mathrm{buffer} \mathrm{(} \mathrm{pH}$ 6.8), were also compared using the model-independent approach of similarity factor $f_{2}$ as a determinant parameter $(27,28)$.

$$
f_{2}=50 \log \left\{\left[1+\frac{1}{n} W_{t} \sum_{t-1}^{a}\left(R_{t}-T_{t}\right)^{2}\right]^{-0.5} \times 100\right\}
$$

where $n$ is the number of data points collected, $R_{t}$ and $T_{t}$ are the percent drug dissolved at each time point for the reference and test tablets, respectively, and $W_{t}$ is an optional weight factor.

Three batches of the selected test formulation (F3 with 12-kg hardness) were prepared at three different occasions to 
find out the reproducibility of the manufacturing process. The optimized tablets (F3 with 12-kg hardness), sealed in plastic bags, were stored in well-closed high-density polyethylene jars and kept under accelerated storage conditions $\left(40 \pm 2^{\circ} \mathrm{C} /\right.$ $75 \pm 5 \%$ relative humidity, $\mathrm{RH}$ ) for 6 months in a stability chamber (Ti-Sc-THH-07-0400, Faisalabad, Pakistan). To determine stability at accelerated storage conditions, the tablets were tested for appearance, friability, hardness, and drug content at 0 times (pre-storage) and after 1, 2, 4, and 6 months' storage.

\section{In Vivo Evaluations}

The in vivo studies on rabbits (Himalayan angora, either sex, weighing $2.2 \pm 0.3 \mathrm{~kg}$ ) were carried out in accordance with the standard protocol approved by the Research and Ethical Committee of Postgraduate Medical Institute, Hayatabad Medical Complex, Peshawar. Rabbits fasted for $24 \mathrm{~h}$ before trial and were divided into two groups, each one having six animals. Selection of rabbits as the animal model for the present study was based on some successfully conducted previously published pharmacokinetic studies $(22,29,30)$. The first group received 4-mg reference conventional tablets and the second group received $4 \mathrm{mg}$ controlled-release (CR) test tablets of risperidone. The rabbits were kept fasted for $12 \mathrm{~h}$ after tablet administration, but given free access to water during the whole period of study. Blood samples $(0.7 \mathrm{~mL}$ each time) were collected from the marginal ear vein at $0,1,2,4,6$, $8,12,24$, and $48 \mathrm{~h}$ in $3-\mathrm{mL}$ test tubes and allowed to clot. A $200-\mu \mathrm{L}$ serum was withdrawn from the clot into another $3-\mathrm{mL}$ test tube and centrifuged (Table Top Centrifuge, model DSC 200A-2; Digisystem Lab, Taiwan) at 2,800 rpm for $10 \mathrm{~min}$. Of the cleared serum, $100 \mu \mathrm{L}$ was transferred to a $10-\mathrm{mL}$ test tube and stored at $-20^{\circ} \mathrm{C}$ until analysis.

Risperidone and 9-hydroxyrisperidone were extracted from the serum samples using an already published liquidliquid extraction method (11). To the $100 \mu \mathrm{L}$ so processed serum sample, $100 \mu \mathrm{L}$ of $1 \mathrm{M}$ sodium bicarbonate and $7 \mathrm{~mL}$ blend of pentane and dichloromethane (85:15) were added and thoroughly mixed with Vortexer (Gyromixer, Pakland, Pakistan) for $2 \mathrm{~min}$. The mixture was centrifuged at 2,800 rpm for $3 \mathrm{~min}$ and the supernatant (organic) layer transferred to 6$\mathrm{mL}$ test tubes for drying under nitrogenous flux. The residue so obtained was dissolved in $100 \mu \mathrm{L}$ acetonitrile with the help of a vortex mixer run for a minute.

Risperidone and its active metabolite (9-hydroxyrisperidone) in rabbit sera were quantified by HPLC-UV by means of a reported method (31) with minor modifications. The HPLC system (Shimadzu) included a communication boss module (model 20A), two independently working pumps (model LC20AT), and an analytical column (PurospharR Star RP, C18e, HiberR RT 250-4.6 (5 $\mu \mathrm{M})$ connected to a UV-Visible detector (SPD-20A). The mobile phase, composed of $130 \mathrm{mM}$ ammonium acetate-methanol-acetonitrile (40:20:40), was run at the flow rate of $0.9 \mathrm{~mL} / \mathrm{min}$.

The concentration-time data of risperidone and 9hydroxyrisperidone from single-dose 4-mg reference tablet and single dose 4-mg CR test tablet were analyzed with Win Nolin ${ }^{\circ}$ Ver. 5.2.1 (Pharsight Corporation, Mountain View, CA, USA). Standard non-compartmental approach (32) was implemented to find out various pharmacokinetic parameters including half-life $\left(t_{1 / 2}\right)$, area under the curve (AUC), and mean residence time (MRT). Unpaired $t$ test with Prism Graph Pad, version 5, was carried out to conclude for the treatment effect (test tablets versus reference tablets). Percent relative bioavailability of the test tablet was calculated with the following equation (33):

$$
\begin{aligned}
& \text { Percent relative bioavailability } \\
& =\frac{\mathrm{AUC}_{0-t}(\text { Test })}{\mathrm{AUC}_{0-t}(\text { Reference })} \times 100
\end{aligned}
$$

Percent risperidone absorbed $\left(P_{\mathrm{a}}\right)$ was plotted against percent risperidone released to determine in vivo-in vitro correlation. Percent risperidone absorbed was determined by the Wagner-Nelson method (34), while percent risperidone released values were taken from the in vitro drug release data.

\section{Statistical Analysis}

Unpaired $t$ test was conducted with Prism Graph Pad, version 5 , to compare the in vitro drug release profiles and the in vivo pharmacokinetic parameters.

\section{RESULTS}

\section{Physicochemical Evaluation of Powder Mix, Granules, and Tablets}

The angle of repose (AR), compressibility index (CI) and Hausner's ratio (HR) for the powder mixture of formulation $\mathrm{F} 1$ were found as $47 \pm 2,26 \pm 3$, and $1.36 \pm 0.16$, respectively, indicating poor flow ability and compressibility. The AR, CI, and HR $(49 \pm 3,28 \pm 4$, and $1.42 \pm 0.13$, respectively) values for the powder mix of formulation $\mathrm{F} 2$ and the AR, CI, and $\mathrm{HR}(55 \pm 4,31 \pm 2$, and $1.45 \pm 0.18$, respectively) values for formulation $\mathrm{F} 3$ also indicate poor flow ability and compressibility. For the prepared granules, the values of $\mathrm{AR}$, $\mathrm{CI}$, and $\mathrm{HR}$ were noted as $31 \pm 2,11 \pm 2$, and $1.13 \pm 0.12$, respectively for formulation $\mathrm{F} 1$; as $33 \pm 2,13 \pm 2$, and $1.16 \pm$ 0.15 , respectively, for formulation $\mathrm{F} 2$; and as $32 \pm 2,12 \pm 1$, and $1.18 \pm 0.12$, respectively, for formulation F3, indicating their good flow ability and compressibility properties. Drug contents of granules of $F 1, F 2$, and F3 were observed as $103 \pm 4 \%$, $102 \pm 3 \%$, and $104 \pm 3 \%$, respectively. The tablets from each lot (9-, 12-, and 15-kg hardness) of formulations F1, F2, and F3 showed $<2 \%$ variation in physical dimensions, $<5 \%$ variation in weights, $<0.5 \%$ friability, and $<5 \%$ variation in drug content, fulfilling the dosage uniformity requirements of Monograph \#<905>, USP XXX

\section{Drug Release Kinetics}

The model formulations F1, F2, and F3, tested for drug release, exhibited drug release periods of nearly 8,12 , and $24 \mathrm{~h}$, respectively, as represented in Fig. 1. The dissolution data obtained during the present study were fitted to the generally used kinetic models; a detailed account of the exploration is presented in Table I. Release rates ( $K$ values) ranged from $11.45 \%$ to $12.09 \%$ per hour in the case of formulation $\mathrm{F} 1$, from $8.13 \%$ to $8.26 \%$ per hour in the case of 


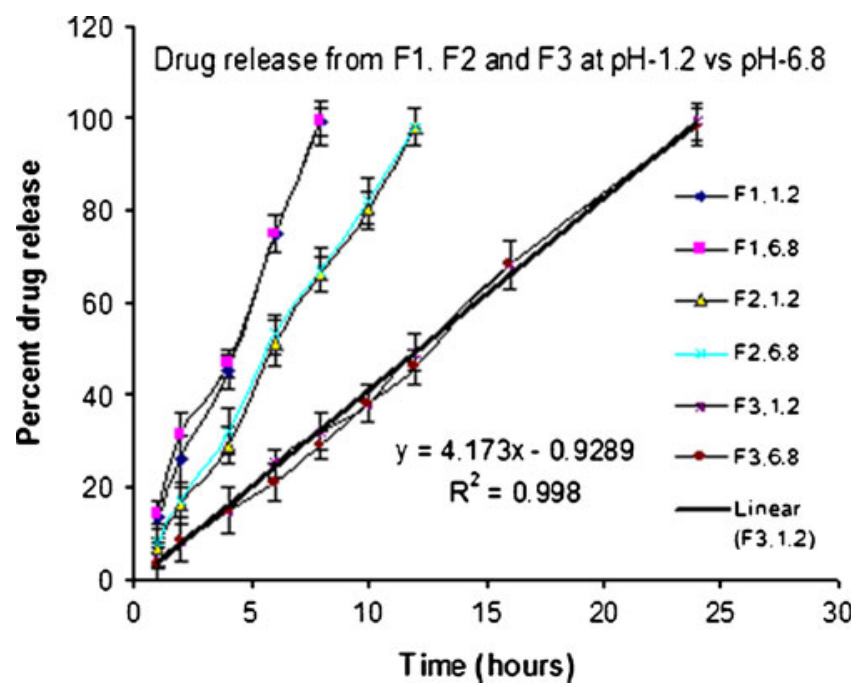

Fig. 1. Comparative release profiles of risperidone from $12-\mathrm{kg}$ hard tablets of model formulations F1 (60\% Methocel® and $30 \%$ Ethocel®), F2 (45\% Methocel ${ }^{\circledR}$ and 45\% Ethocel $\left.{ }^{\circledR}\right)$, and F3 (30\% Methocel ${ }^{\circledR}$ and $60 \%$ Ethocel $\left.{ }^{\circledR}\right)$ using dissolution media of $0.1 \mathrm{~N} \mathrm{HCl}$ with $\mathrm{pH} 1.2(\mathrm{~F} 1,1.2 ; \mathrm{F} 2,1.2 ; \mathrm{F} 3,1.2)$ and phosphate buffer with $\mathrm{pH} 6.8(\mathrm{~F} 1,6.8 ; \mathrm{F} 2,6.8 ; \mathrm{F} 3,6.8)$, stirred with paddles run at $50 \mathrm{rpm}$

formulation $\mathrm{F} 2$, and from $4.10 \%$ to $4.20 \%$ per hour using $0.1 \mathrm{~N} \mathrm{HCl}(\mathrm{pH} 1.2)$ and phosphate buffer ( $\mathrm{pH}$ 6.8) as dissolution media, as shown in Table I. Release exponent $n$ and/or goodness-of-fit test (linearity of the curve) were used as standards for selecting the most appropriate model. The observed values of the release exponent $n$ more or less ranged from 0.86 to 1.14 of formulations $\mathrm{F} 1, \mathrm{~F} 2$, and F3 in both $0.1 \mathrm{~N} \mathrm{HCl}$ and phosphate buffer. Changes in the hardness of tablets and $\mathrm{pH}$ of the dissolution media did not affect significantly $(p>0.05)$ the release rates and mechanism (see Table I and Figs. 2 and 3). The drug release profiles of the various lots (i.e., 9-, 12-, and 15-kg hard tablets) of formulation $\mathrm{F}$ 3, determined in the dissolution media of $0.1 \mathrm{~N}$ $\mathrm{HCl}$ and phosphate buffer, were compared using a modelindependent pairwise approach of similarity factor $f_{2}$. The similarity factor $f_{2}$ values, calculated as $80.96,82.53$, and 84.95 for 9-, 12-, and 15-kg hard tablets, respectively, of formulation F3, showed a good level of equivalence in dissolution profiles obtained for the tablets at $\mathrm{pH} 6.8$ (used as test) versus $\mathrm{pH} 1.2$ (used as reference).

The test tablet containing 30\% Methocel® and $60 \%$ Ethocel® (F3) with 12-kg hardness was selected as the optimized one (based on its release kinetics of zero order) for further studies. Insignificant difference was observed in the drug contents $(102 \pm 3,103 \pm 2$, and $100 \pm 3)$ of the test tablets produced at three different occasions. Accelerated storage conditions, $40 \pm 2^{\circ} \mathrm{C} / 75 \pm 5 \% \mathrm{RH}($ mean $\pm \mathrm{SD})$ did not affect significantly the drug content, weight variation, friability, hardness, and appearance of the CR test tablets for the whole 6-month study period (Table II).

\section{In Vivo Evaluation}

During HPLC-UV analysis, the retention times for 9hydroxyrisperidone and risperidone were noted as 4.02 and $4.62 \mathrm{~min}$, respectively. The mean absolute recoveries of

Table I. Effect of Formulation (F1, F2, and F3), Dissolution Media (pH 1.2 and 6.8) and Tablet Hardness (9, 12, and 15 kg) on the Release Kinetics of Risperidone from Its Extended-Release Tablets

\begin{tabular}{|c|c|c|c|c|c|c|c|c|c|c|c|c|}
\hline \multirow[b]{2}{*}{ Formulation } & \multirow[b]{2}{*}{ Hardness (kg) } & \multicolumn{2}{|c|}{ Zero order } & \multicolumn{2}{|c|}{ Higuchi } & \multicolumn{2}{|c|}{ First order } & \multicolumn{2}{|c|}{ Hixon-Crowel } & \multicolumn{2}{|c|}{ Korsemeyer } & \multirow{2}{*}{$\begin{array}{l}\text { Results } \\
\text { Mechanism of } \\
\text { drug release }\end{array}$} \\
\hline & & $K$ & $R^{2}$ & $K$ & $R^{2}$ & $K$ & $R^{2}$ & $K$ & $R^{2}$ & $n$ & $R^{2}$ & \\
\hline \multicolumn{13}{|c|}{$\mathrm{pH}$ of the dissolution medium $=1.2$} \\
\hline \multirow[t]{3}{*}{$\mathrm{F} 1$} & 9 & 12.09 & 0.998 & 45.94 & 0.971 & -0.213 & 0.816 & -0.311 & 0.982 & 0.88 & 0.994 & Zero order ${ }^{a}$ \\
\hline & 12 & 12.29 & 0.996 & 46.74 & 0.969 & -0.247 & 0.778 & -0.0317 & 0.977 & 0.94 & 0.994 & Zero order ${ }^{b}$ \\
\hline & 15 & 11.91 & 0.998 & 45.30 & 0.973 & -0.212 & 0.821 & -0.302 & 0.979 & 0.86 & 0.997 & Zero order $^{a}$ \\
\hline \multirow[t]{3}{*}{$\mathrm{F} 2$} & 9 & 8.13 & 0.999 & 36.22 & 0.974 & -0.124 & 0.768 & -0.231 & 0.952 & 1.05 & 0.993 & Zero order $^{b}$ \\
\hline & 12 & 8.26 & 0.997 & 36.87 & 0.976 & -0.126 & 0.783 & -0.235 & 0.952 & 1.07 & 0.995 & Zero order ${ }^{b}$ \\
\hline & 15 & 8.13 & 0.996 & 36.29 & 0.976 & -0.113 & 0.794 & -0.229 & 0.962 & 1.14 & 0.994 & Zero order ${ }^{b}$ \\
\hline \multirow[t]{3}{*}{ F3 } & 9 & 4.11 & 0.997 & 23.75 & 0.954 & -0.059 & 0.839 & -0.128 & 0.906 & 1.07 & 0.987 & Zero order $^{b}$ \\
\hline & 12 & 4.17 & 0.998 & 24.06 & 0.949 & -0.075 & 0.782 & -0.127 & 0.928 & 1.01 & 0.998 & Zero order $^{b}$ \\
\hline & 15 & 4.10 & 0.998 & 23.45 & 0.962 & -0.065 & 0.819 & -0.125 & 0.917 & 0.99 & 0.997 & Zero order ${ }^{b}$ \\
\hline \multicolumn{13}{|c|}{$\mathrm{pH}$ of the dissolution medium $=6.8$} \\
\hline \multirow[t]{3}{*}{$\mathrm{F} 1$} & 9 & 11.45 & 0.998 & 43.57 & 0.975 & -0.189 & 0.833 & -0.287 & 0.978 & 0.81 & 0.998 & Zero order $^{a}$ \\
\hline & 12 & 11.85 & 0.993 & 45.18 & 0.973 & -0.246 & 0.780 & -0.297 & 0.861 & 0.88 & 0.980 & Zero order ${ }^{a}$ \\
\hline & 15 & 11.55 & 0.994 & 44.23 & 0.982 & -0.212 & 0.840 & -0.285 & 0.958 & 0.83 & 0.985 & Zero order ${ }^{a}$ \\
\hline \multirow[t]{3}{*}{$\mathrm{F} 2$} & 9 & 8.40 & 0.997 & 37.14 & 0.976 & -0.143 & 0.728 & -0.242 & 0.951 & 1.11 & 0.993 & Zero order ${ }^{b}$ \\
\hline & 12 & 8.19 & 0.998 & 36.69 & 0.982 & -0.127 & 0.799 & -0.229 & 0.948 & 1.02 & 0.998 & Zero order $^{b}$ \\
\hline & 15 & 8.18 & 0.994 & 36.21 & 0.956 & -0.115 & 0.799 & -0.234 & 0.965 & 1.01 & 0.978 & Zero order ${ }^{b}$ \\
\hline \multirow[t]{3}{*}{ F3 } & 9 & 4.17 & 0.997 & 23.85 & 0.954 & -0.076 & 0.789 & -0.125 & 0.926 & 0.98 & 0.992 & Zero order ${ }^{b}$ \\
\hline & 12 & 4.18 & 0.996 & 23.98 & 0.939 & -0.065 & 0.811 & -0.131 & 0.927 & 1.08 & 0.994 & Zero order $^{b}$ \\
\hline & 15 & 4.20 & 0.995 & 24.25 & 0.947 & -0.074 & 0.761 & -0.126 & 0.924 & 0.99 & 0.992 & Zero order ${ }^{b}$ \\
\hline
\end{tabular}

$K, R^{2}$, and $n$ represent the release rate constant, coefficient of determination, and release exponent, respectively. F1 contains $60 \%$ Methocel ${ }^{\circledR}$ and 30\% Ethocel®; F2 contains 45\% Methocel® and 45\% Ethocel®; and F3 contains 30\% Methocel® and 60\% Ethocel@

${ }^{a}$ Decision was made on the basis of the values of $R^{2}$

${ }^{b}$ Decision was made on the basis of the values of both $n$ and $R^{2}$ 


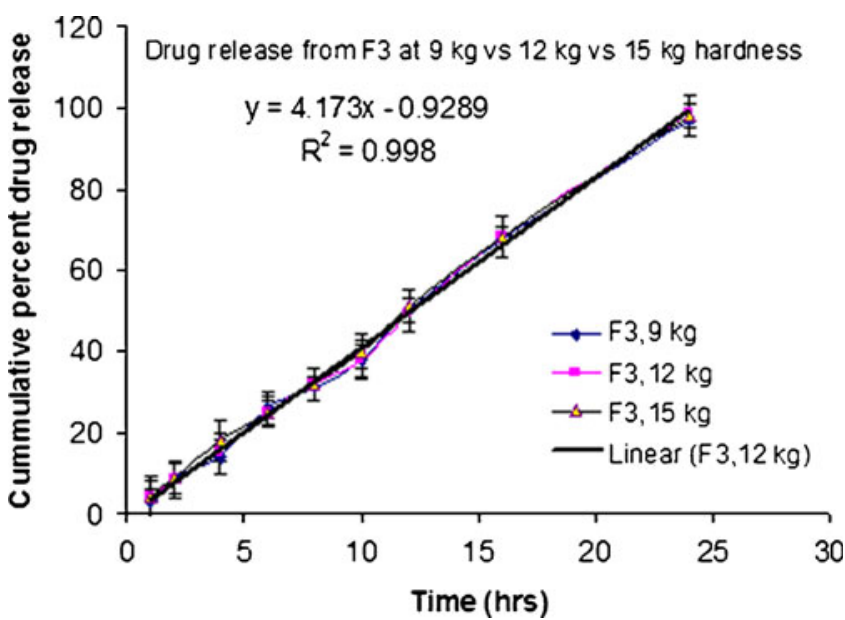

Fig. 2. Comparative release profiles of risperidone from 9- 12-, and $15-\mathrm{kg}$ hard tablets of model formulation F3 (30\% Methocel® and $60 \%$ Ethocel ${ }^{\circledR}$ ) using dissolution media of $0.1 \mathrm{~N} \mathrm{HCl}, \mathrm{pH} 1.2$, stirred with paddles run at $50 \mathrm{rpm}$

risperidone and 9-hydroxyrisperidone were observed as $91.5 \pm$ $3 \%$ and $90 \pm 2 \%$, respectively.

The CR test tablet exhibited a significantly $(p<0.05)$ optimized peak serum concentration $\left(C_{\max }\right)$ and a significantly $(p<0.05)$ extended peak time $\left(T_{\max }\right.$, hours $)$ and mean residence time $\left(\mathrm{MRT}_{0-48} \mathrm{~h}\right)$ with respect to the active moiety, risperidone alone, and 9-hydroxyrisperidone alone. The areas under the curves $\left(\mathrm{AUC}_{0-48 \mathrm{~h}}\right.$ and $\left.\mathrm{AUC}_{0-\text { inf }}\right)$ of the active moiety for the test and the reference tablets were not significantly $(p<0.05)$ different (see Fig. 4 and Table III), indicating bioequivalence of the $\mathrm{CR}$ test tablets with the reference conventional tablets. Significant extension $(p<0.05)$ in the half-lives of risperidone alone and 9-hydroxyrisperidone alone were shown by the CR test tablet, indicating the success of the formulation (see Fig. 4 and Table III). The halflife of the active moiety from the CR test tablet was noted as $18.14 \pm 3.45 \mathrm{~h}$, while that of the reference tablet was $15.27 \pm$

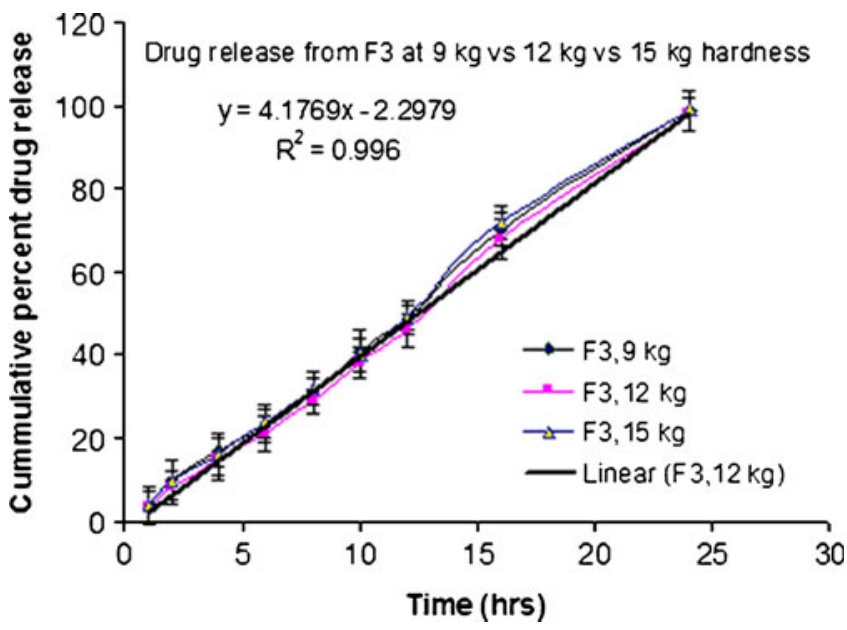

Fig. 3. Comparative release profiles of risperidone from 9-, 12-, and $15-\mathrm{kg}$ hard tablets of model formulations F3 (30\% Methocel ${ }^{\circledR}$ and $60 \%$ Ethocel®) using dissolution media of phosphate buffer, $\mathrm{pH} 6.8$, stirred with paddles run at $50 \mathrm{rpm}$
$2.092 \mathrm{~h}$, indicating successful development of the CR formulation.

\section{Relative Bioavailability and In Vitro and In Vivo Correlation}

The percent risperidone absorbed $\left(P_{\mathrm{a}}\right)$ when plotted against the percent risperidone released $\left(P_{\mathrm{r}}\right)$ showed a good correlation $\left(R^{2}=0.7293\right)$ between the drug absorbed in vivo and the drug released in vitro (Fig. 5).

\section{DISCUSSION}

Commonly encountered noncompliance to antipsychotic drug therapy $(3,35)$ leads to an almost double re-hospitalization from relapse (36). Therefore, a controlled-release tablet of risperidone was developed to optimize its blood level, minimize its side effects, and ultimately improve its treatment adherence.

During pilot studies, the widely used release-retarding hydrophilic polymer Methocel ${ }^{\circ}$ K100LV-CR was tried alone starting from $20 \%$ up to $60 \%$ of tablet weight (with $10 \%$ increments), but it could hardly extend the drug release period from $2 \mathrm{~h}$ up to $8 \mathrm{~h}$. Then, the percentage of the Methocel® was further increased step by step in the same way up to $90 \%$ of tablet weight, but the release period was not extended to any appreciable extent. Therefore, a part of the Methocel ${ }^{\circledR}$ was substituted by the hydrophobic Ethocel ${ }^{\circledR}$ standard 7FP premium for extending the release period up to $24 \mathrm{~h}$.

In a total $90 \%$ polymeric blend, $60 \%$ Methocel® and $30 \%$ Ethocel® (F1) could hardly maintain the release period of $8 \mathrm{~h}$. However, the value of the release exponent $n$ was raised from an anomalous drug release $(n<0.89)$ to a zeroorder drug release $(n \geq 0.89)$ pattern using $0.1 \mathrm{~N} \mathrm{HCl}$ (pH 1.2). Nearly the same results were observed for the tablets in phosphate buffer $(\mathrm{pH}$ 6.8). A major difficulty experienced after the inclusion of $30 \%$ Ethocel ${ }^{\circledR}$ in formulation F1 was the poor flowability and compressibility of the powder mixture, which led us to use the dry granulationslugging method for manufacturing the tablets. The flow and compressibility characteristics of the powder mixtures were sufficiently improved by the successful use of the dry granulation-slugging method. The method was selected because it does not allow a chance of decomposition of drugs by hydrolysis, as occurs in the case of wet granulation method. Thereafter, further substitution of $15 \%$ Methocel® by Ethocel ${ }^{\circledR}(\mathrm{F} 2,45: 45 \%)$ extended the release period up to $12 \mathrm{~h}$, with $n$ values $\geq 0.89$ and/or $R^{2}$ falling near to 1 (linear curve), indicating zero-order kinetics. In the case of formulation F3, further substitution of $15 \%$ Methocel ${ }^{\circledR}$ by Ethocel ${ }^{\circledR}\left(30 \%\right.$ Methocel ${ }^{\circledR}$ and $60 \%$ Ethocel $\left.{ }^{\circledR}\right)$ could extend the release period up to $24 \mathrm{~h}$ with zero-order kinetics, as shown in Fig. 1 and Table I.

An expected but disproportional reduction in the release rates with an increase in the concentration of the hydrophobic Ethocel ${ }^{\circledR}$ might be caused by the slow penetrability of water for hydration of the matrix due to the hydrophobic character of the Ethocel ${ }^{\circledR}$ particles. Additionally, the insoluble particles of Ethocel ${ }^{\circledR}$ entangled in the gel layer of Methocel ${ }^{\circledR}$ were perhaps performing the role of barrier to drug release. This idea is in line with some previously published studies $(25,37)$. 
Table II. Stability Indicating Parameters Determined for the Test Tablet of Risperidone at $40 \pm 2^{\circ} \mathrm{C} / 75 \pm 5 \% \mathrm{RH}(\mathrm{Mean} \pm \mathrm{SD})$

\begin{tabular}{|c|c|c|c|c|c|}
\hline Testing time & Drug content (\%) & Weight variation (\%) & Friability (\%) & Hardness (kg) & Appearance \\
\hline At 0 time (pre-storage) & $103 \pm 3$ & $4 \pm 0.3$ & $0.45 \pm 0.02$ & $12.0 \pm 0.3$ & whitish \\
\hline After 1 month & $104 \pm 2$ & $4 \pm 0.4$ & $0.41 \pm 0.03$ & $12.0 \pm 0.3$ & whitish \\
\hline After 2 months & $103 \pm 3$ & $3 \pm 0.4$ & $0.51 \pm 0.03$ & $12.0 \pm 0.3$ & whitish \\
\hline After 4 months & $101 \pm 3$ & $3 \pm 0.3$ & $0.43 \pm 0.02$ & $12.2 \pm 0.4$ & whitish \\
\hline After 6 months & $100 \pm 2$ & $4 \pm 0.4$ & $0.68 \pm 0.02$ & $12.4 \pm 0.4$ & whitish \\
\hline
\end{tabular}

Since both Methocel® and Ethocel ${ }^{\circledR}$ possess binding and matrix-forming characteristics (38), tablets of high quality (optimum friability and desired hardness level) were produced. As zero-order drug release supplies a constant amount of drug for absorption and maintains a constant level of plasma concentration (39), many researchers have sought to formulate matrices for zero-order release pattern, but few have been successful $(24,25)$.

To elucidate the mechanism of drug release from risperidone controlled-release tablets, dissolution data for the first $60 \%$ of drug release (40) were fitted to the exponential equation (26). The release exponent $n$ was calculated through the slope of the straight line upon fitting data into the Korsemeyer-Peppas model $(26,41)$. In the case of cylinders (i.e., tablets), the value of $n \leq 0.45$ shows Fickian release; values of $0.45<n<0.89$ show anomalous transport, while the value of $n \geq 0.89$ shows a zero-order release $(42,43)$.

Fickian diffusion proposes the diffusion of drug through pores of the matrix and zero-order express release of drug with erosion of the polymeric chains, while anomalous transport reveals release of drug by a combined process of diffusion and erosion (41). The decisive factor for selecting the most appropriate model (among the mathematical models usually employed in this connection) was based on the $n$ value and/or goodness-of-fit test (i.e., linearity of the curves, where the coefficient of determination $R^{2}$ approaches 1 ) values.

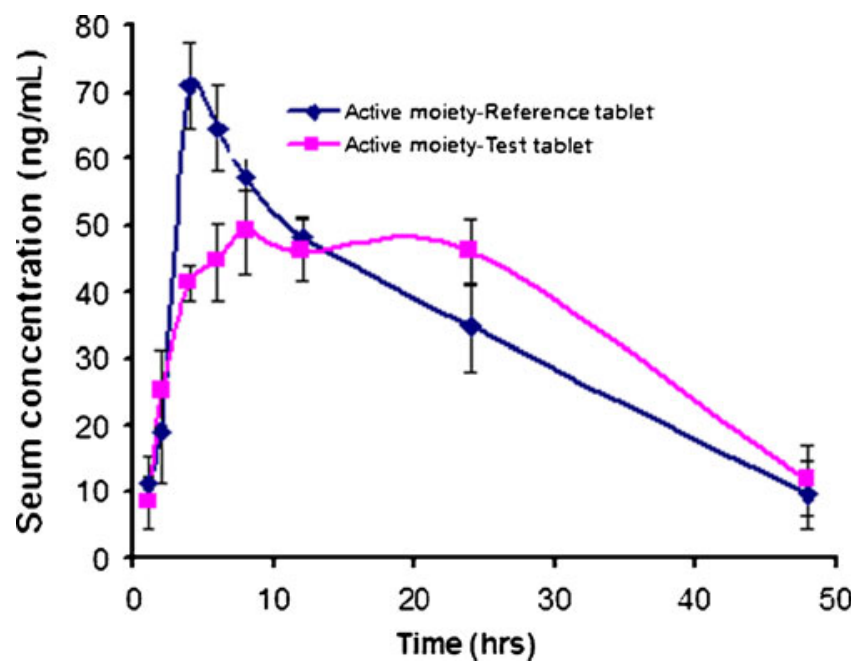

Fig. 4. Comparative serum concentration-time profiles of active moiety-reference tablet and active moiety-test tablet obtained from reference and test tablets, respectively, following their oral administration to rabbits (mean $\pm \mathrm{SD}, n=6$ ). Active moiety refers to the combined concentration of risperidone and 9-hydroxyrisperidone
Use of a larger proportion of the polymer blend (i.e., $90 \%$ ) was compromised for achieving the 24-h release period with zero-order kinetics. The aforementioned objectionable point is qualified by some earlier investigations where $89.5 \%$ of fine particle ethyl cellulose (23) and 90\% Methocel- and Ethocel-based blends (25) were used to extend the drug release period up to $24 \mathrm{~h}$. The need for so much higher concentrations of the polymeric blend in the present study may be due to the low-viscosity gel former Methocel ${ }^{\circledR}, \mathrm{K} 100$ LV-CR (44), leading to rapid disentanglement and erosion of the matrices.

Drug release mechanism based on the values of $n$ and/or $R^{2}$ showed a zero-order release pattern of risperidone at both $\mathrm{pH} 1.2$ and $\mathrm{pH} 6.8$ for all (9-, 12-, and 15-kg hard tablets) three formulations F1, F2, and F3.

Application of a higher compression force to the designed matrices regularly caused an increase in tablet hardness, but the drug release kinetics were not affected in both dissolution media, which is in line with some previous studies $(25,45)$. It means that the porosity and/or tortuosity of the prepared tablets upon hydration were not affected by the increase in tablet hardness, which is in line with the observations of some other groups of investigators $(45,46)$.

As the $\mathrm{pH}$ in GIT is not uniform, influence of changes in $\mathrm{pH}$ on the drug release kinetics was also studied (see Figs. 2 and 3). Methocel® K100 LV-CR (hydroxypropyl methylcellulose) is a cellulose derivative (with methoxyl and hydroxypropyl substituents on a $\beta$-o-glucopyranosyl ring backbone) resistant to changes in $\mathrm{pH}$ of the dissolution medium in the range of $2-13$, so it is relatively stable (47). Similarly, Ethocel®, a cellulose derivative (with ethoxyl substitution on anhydroglucose ring backbone), is insoluble in water; thus, its release properties are less affected by the changes in $\mathrm{pH}$ (48). Therefore, in the present study, risperidone release from a blend of these polymers was not affected by changes in $\mathrm{pH}$ of the dissolution media.

The similarity factor $f_{2} \geq 50$ indicates an average difference of not more than $10 \%$ at the sample time points $(27,28)$. In the present study, higher values of the similarity factor $f_{2}$ (i.e., >80) for the 9-, 12-, and $15-\mathrm{kg}$ hard tablets of formulation F3 indicate negligible difference of the tablets' dissolution profiles in phosphate buffer $(\mathrm{pH} 6.8)$ versus in $0.1 \mathrm{~N}$ $\mathrm{HCl}$ ( $\mathrm{pH}$ 1.2). The aforementioned values of $f_{2}$ calculated for the tablets have further strengthened our finding that the $\mathrm{pH}$ variations did not significantly affect the drug release from the matrices designed in the present study.

The comparative in vivo studies of the test tablet and the reference conventional Risperdal ${ }^{\circledR}$ tablet in rabbits exhibited the ability of the former tablet to maintain a fairly optimized serum concentration of the drug for an extended period (see Fig. 4). Significant extension in half-life $\left(t_{1 / 2}\right)$ and time for 
Table III. Pharmacokinetic Parameters Determined in Rabbit Sera Following Oral Administration of 4 mg Reference Conventional Tablets and $4 \mathrm{mg}$ CR Test Tablets (Mean \pm SEM)

\begin{tabular}{|c|c|c|}
\hline Pharmacokinetic parameter determined as & Reference tablets & Test tablets \\
\hline \multicolumn{3}{|l|}{ Active moiety (risperidone plus 9-hydroxyrisperidone) } \\
\hline Half-life, $t_{1 / 2}(\mathrm{~h})$ & $15.27 \pm 2.092$ & $18.14 \pm 3.45$ \\
\hline Time of maximum plasma concentration, $T_{\max }(\mathrm{h})$ & $4.67 \pm 0.42$ & $11.00 \pm 2.72 *$ \\
\hline Maximum plasma concentration, $C_{\max }(\mathrm{ng} / \mathrm{mL})$ & $72.83 \pm 2.12$ & $51.50 \pm 1.80 * * *$ \\
\hline Area under curve, $\mathrm{AUC}_{0-48 \mathrm{~h}}(\mathrm{ng} \mathrm{h} / \mathrm{mL})$ & $1,609.00 \pm 70.72$ & $1,702.00 \pm 54.20$ \\
\hline Area under curve-AUC $\mathrm{A}_{0-\text { inf }}(\mathrm{ng} \mathrm{h} / \mathrm{mL})$ & $1,853.00 \pm 146.80$ & $2,061.00 \pm 184.80$ \\
\hline Mean residence time, MRT $_{0-48} \mathrm{~h}(\mathrm{~h})$ & $17.24 \pm 0.64$ & $19.40 \pm 0.55^{*}$ \\
\hline \multicolumn{3}{|l|}{ Risperidone (alone) } \\
\hline Half-life, $T_{1 / 2}(\mathrm{ng} \mathrm{h} / \mathrm{mL})$ & $5.07 \pm 0.34$ & $15.32 \pm 2.08 * * *$ \\
\hline Time of maximum plasma concentration, $T_{\max }(\mathrm{h})$ & $4.17 \pm 0.17$ & $3.67 \pm 0.33$ \\
\hline Maximum plasma concentration, $C_{\max }(\mathrm{ng} / \mathrm{mL})$ & $56.00 \pm 2.66$ & $26.00 \pm 1.27 * * *$ \\
\hline Area under curve, $\mathrm{AUC}_{0-48}$ h $(\mathrm{ng} \mathrm{h} / \mathrm{mL})$ & $499.8 \pm 26.72$ & $589.0 \pm 19.60 *$ \\
\hline Area under curve, $\mathrm{AUC}_{0-\text { inf }}(\mathrm{ng} \mathrm{h} / \mathrm{mL})$ & $518.8 \pm 21.64$ & $835.5 \pm 107.4^{*}$ \\
\hline Mean residence time, $\mathrm{MRT}_{\text {all }}(\mathrm{h})$ & $7.289 \pm 0.57$ & $15.01 \pm 1.09 * * *$ \\
\hline \multicolumn{3}{|l|}{ 9-Hydroxyrisperidone (alone) } \\
\hline Half-life, $t_{1 / 2}(\mathrm{ng} \mathrm{h} / \mathrm{mL})$ & $17.50 \pm 2.11$ & $74.72 \pm 16.06 * * *$ \\
\hline Time of maximum concentration, $T_{\max }(\mathrm{h})$ & $14.67 \pm 3.04$ & $14.67 \pm 3.04$ \\
\hline Maximum plasma concentration, $C_{\max }(\mathrm{ng} / \mathrm{mL})$ & $33.83 \pm 1.276$ & $21.00 \pm 1.789 * * *$ \\
\hline Area under curve, $\mathrm{AUC}_{0 \mathrm{All}}(\mathrm{ng} \times \mathrm{h} / \mathrm{mL})$ & $1,109 \pm 54.99$ & $745.2 \pm 50.23^{* * *}$ \\
\hline Are under curve, $\mathrm{AUC}_{0-\text { inf }}(\mathrm{ng} \mathrm{h} / \mathrm{mL})$ & $1,594 \pm 291.0$ & $2,280 \pm 384.5$ \\
\hline Mean residence time, $\mathrm{MRT}_{0-48 \mathrm{~h}}(\mathrm{~h})$ & $21.05 \pm 0.7215$ & $24.08 \pm 0.4496 * *$ \\
\hline
\end{tabular}

$* P<0.05, * * P<0.001, * * * P<0.0001$ (values are significantly different between means of reference and test tablets of risperidone, mean \pm SEM)

peak concentration $\left(T_{\max }\right)$ of risperidone and 9-hydroxyrisperidone from the test tablet is indicative of drug release at a slower rate for an extended time interval. Bioequivalence of the test tablet to the reference conventional Risperdal ${ }^{\circledR}$ tablet is indicated by the AUCs of the tablets concerned (see Table II). The relative bioavailability of test tablets, calculated as $100 \%$, also indicates the suitability of the formulation. An optimized serum drug concentration from the test tablet for an extended time (see Fig. 4) proves the successful development of the controlled-release formulation.

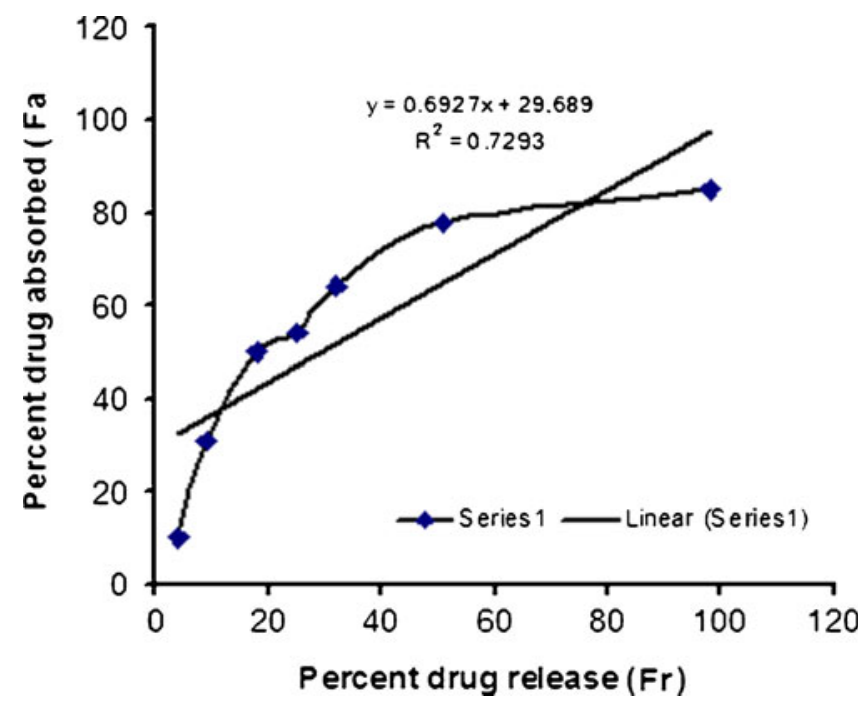

Fig. 5. Percent drug absorbed $\left(P_{\mathrm{a}}\right)$ plotted against percent drug released $\left(P_{\mathrm{r}}\right)$ at times $1,2,4,6,8,12$, and $24 \mathrm{~h}$ to determine the in vitro and in vivo correlation of risperidone controlled-release test tablet
The percent drug absorbed was calculated with the Wagner and Nelson method (34) followed by in vitro-in vivo correlation $\left(R^{2}\right)$ determination, which turned out to be 0.7293 for the test tablet (see Fig. 5). The results revealed a good level A (point to point) correlation of drug absorbed with the amount of drug released.

\section{CONCLUSION}

The blend of Methocel® K100LV-CR and the Ethocel® standard 7FP premium was successfully used in preparing the $\mathrm{CR}$ tablet of risperidone. The blend exhibited a $\mathrm{pH}$-independent zero-order kinetics. Ethocel ${ }^{\circledR}$ played a major role in controlling drug release, while the gel layer of Methocel® proved its worth in maintaining solidarity of the matrix. The CR test tablet, based on its optimized peak concentration and bioequivalence to the conventional Risperdal ${ }^{\circledR}$ tablet, may be used for better therapeutic outcomes of risperidone.

\section{ACKNOWLEDGMENTS}

We are thankful to the University of Peshawar for providing partial financial support. We are also thankful to Colorcon Asia Pacific, India, for providing Ethocel standard 7FP premium and Methocel K100LV-CR as gift samples. We are obliged to Bryon Pharma Ltd., Khyber Pakhtoonkhwa (Pakistan), for supplying risperidone as a gift sample and offering their tablet manufacturing facilities.

Declaration of Interest The authors report no declaration of interest. 


\section{REFERENCES}

1. Hendset M, Haslemo T, Rudberg I, Refsum H, Molden E. The complexity of active metabolites in therapeutic drug monitoring of psychotropic drugs. Pharmacopsychiatry. 2006;39(4):121-7.

2. Leon J, Susce M, Pan R, Wedlund P, Orrego M, Diaz F. A study of genetic (CYP2D6 and ABCB1) and environmental (drug inhibitors and inducers) variables that may influence plasma risperidone levels. Pharmacopsychiatry. 2007;40(3):93-102.

3. Ascher-Svanum H, Faries D, Zhu B, Ernst F, Swartz M, Swanson J. Medication adherence and long-term functional outcomes in the treatment of schizophrenia in usual care. J Clin Psychiatry. 2006;67(3):453.

4. Morken G, Widen J, Grawe R. Non-adherence to antipsychotic medication, relapse and rehospitalisation in recent-onset schizophrenia. BMC Psychiatry. 2008;8(1):32.

5. Robinson DG, Woerner MG, Alvir JMJ, Bilder RM, Hinrichsen GA, Lieberman JA. Predictors of medication discontinuation by patients with first-episode schizophrenia and schizoaffective disorder. Schizophr Res. 2002;57(2-3):209-19.

6. Ray W, Chung C, Murray K, Hall K, Stein C. Atypical antipsychotic drugs and the risk of sudden cardiac death. N Engl J Med. 2009;360(3):225.

7. Sweetman S. Martindale, the complete drug reference. 35th ed. London: The Pharmaceutical Press; 2008.

8. Jung S, Kim K, Cho H, Jung I, Park P, Byun W, et al. Cytochrome P450 3A inhibitor itraconazole affects plasma concentrations of risperidone and 9-hydroxyrisperidone in schizophrenic patients. Clin Pharmacol Ther. 2005;78(5):520-8.

9. Spina E, Avenoso A, Facciolà G, Scordo M, Ancione M, Madia A. Plasma concentrations of risperidone and 9-hydroxyrisperidone during combined treatment with paroxetine. Ther Drug Monit. 2001;23(3):223.

10. Bondolfi G, Eap C, Bertschy G, Zullino D, Vermeulen A, Baumann P. The effect of fluoxetine on the pharmacokinetics and safety of risperidone in psychotic patients. Pharmacopsychiatry. 2002;35(2):50-6.

11. Aravagiri M, Marder S, Wirshing D, Wirshing W. Plasma concentrations of risperidone and its 9-hydroxy metabolite and their relationship to dose in schizophrenic patients: simultaneous determination by a high performance liquid chromatography with electrochemical detection. Pharmacopsychiatry. 1998;31:1029.

12. Heykants J, Huang M, Mannens G, Meuldermans W, Snoeck E, Van Beijsterveldt L, et al. The pharmacokinetics of risperidone in humans: a summary. J Clin Psychiatry. 1994;55(MAI):13-7.

13. Hiemke C, Dragicevic A, Gründer G, Hätter S, Sachse J, Vernaleken I, et al. Therapeutic monitoring of new antipsychotic drugs. Ther Drug Monit. 2004;26(2):156.

14. Mauri M, Volonteri L, Colasanti A, Fiorentini A, De Gaspari I, Bareggi S. Clinical pharmacokinetics of atypical antipsychotics: a critical review of the relationship between plasma concentrations and clinical response. Clin Pharmacokinet. 2007;46(5):359-88.

15. Keith S. Advances in psychotropic formulations. Prog Neuro Psychopharmacol Biol Psychiatry. 2006;30(6):996-1008.

16. Meltzer H, Bobo W, Nuamah I, Lane R, Hough D, Kramer M, et $a l$. Efficacy and tolerability of oral paliperidone extended-release tablets in the treatment of acute schizophrenia: pooled data from three 6-week, placebo-controlled studies. J Clin Psychiatry. 2008;69(5):817.

17. Barakat N, Elbagory I, Almurshedi A. Formulation, release characteristics and bioavailability study of oral monolithic matrix tablets containing carbamazepine. AAPS PharmSciTech. 2008;9 (3):931-8.

18. Vivek K, Reddy H, Murthy R. Investigations of the effect of the lipid matrix on drug entrapment, in vitro release, and physical stability of olanzapine-loaded solid lipid nanoparticles. AAPS PharmSciTech. 2007;8(4):16-24.

19. Ravi P, Ganga S, Saha R. Design and study of lamivudine oral controlled release tablets. AAPS PharmSciTech. 2007;8(4):167-75.

20. Merchant H, Shoaib H, Tazeen J, Yousuf R. Once-daily tablet formulation and in vitro release evaluation of cefpodoxime using hydroxypropyl methylcellulose: a technical note. AAPS PharmSciTech. 2006;7(3):178-83.
21. Jagdale S, Agavekar A, Pandya S, Kuchekar B, Chabukswar A. Formulation and evaluation of gastroretentive drug delivery system of propranolol hydrochloride. AAPS PharmSciTech. 2009;10(3):1071-9.

22. Nagarwal R, Ridhurkar D, Pandit J. In vitro release kinetics and bioavailability of gastroretentive cinnarizine hydrochloride tablet. AAPS PharmSciTech. 2010;11(1):294-303.

23. Agrawal A, Neau S, Bonate P. Wet granulation fine particle ethylcellulose tablets: effect of production variables and mathematical modeling of drug release. AAPS J. 2003;5(2):48-60.

24. Jamzad S, Fassihi R. Development of a controlled release low dose class II drug — glipizide. Int J Pharm. 2006;312(1-2):24-32.

25. Badshah A, Subhan F, Rauf K. Controlled release matrix tablets of olanzapine: influence of polymers on the in vitro release and bioavailability. AAPS PharmSciTech. 2010;11:1397-404.

26. Korsmeyer R, Gurny R, Doelker E, Buri P, Peppas N. Mechanisms of solute release from porous hydrophilic polymers. Int J Pharm. 1983;15(1):25-35.

27. FDA. Guidance for industry. Dissolution testing of immediate release solid oral dosage forms. Rockville, MD; 1997.

28. Shah VP, Tsong Y, Sathe P, Liu JP. In vitro dissolution profile comparison-statistics and analysis of the similarity factor, $f_{2}$. Pharm Res. 1998;15(6):889-96.

29. Malkawi A, Al-Ghananeem A, Crooks P. Development of a GCMS assay for the determination of fentanyl pharmacokinetics in rabbit plasma after sublingual spray delivery. AAPS J. 2008;10 (2):261-7.

30. Charde S, Mudgal M, Kumar L, Saha R. Development and evaluation of buccoadhesive controlled release tablets of lercanidipine. AAPS PharmSciTech. 2008;9(1):182-90.

31. Cho H, Lee Y. Pharmacokinetics and bioequivalence evaluation of risperidone in healthy male subjects with different CYP2D6 genotypes. Arch Pharm Res. 2006;29(6):525-33.

32. Gibaldi M, Perrier D. One compartment model. In: Gibaldi M, Perrier D, editors. Pharmacokinetics. 2nd ed. New York: Marcel Dekker; 1982. p. 1-49.

33. Shargel L, Yu A. Bioavailability and bioequivalence. In: Applied biopharmaceutics and pharmacokinetics, 5th ed. New York: McGraw-Hill, Medical Publishing Company; 2005. p. 453-98.

34. Wagner JG, Nelson E. Kinetic analysis of blood levels and urinary excretion in the absorptive phase after single doses of drug. J Pharm Sci. 1964;53:1392-403.

35. Weiden P, Mackell J, McDonnell D. Obesity as a risk factor for antipsychotic noncompliance. Schizophr Res. 2004;66(1):51-7.

36. Svarstad B, Shireman T, Sweeney J. Using drug claims data to assess the relationship of medication adherence with hospitalization and costs. Psychiatr Serv. 2001;52(6):805.

37. Howard J, Timmins P. Controlled release formulation. US Patent 4,792,452; 1988.

38. Chowhan Z. Role of binders in moisture-induced hardness increase in compressed tablets and its effect on in vitro disintegration and dissolution. J Pharm Sci. 1980;69(1):1-3.

39. Shah A. Design of oral sustained release drug delivery systems: in-vitro/in-vivo considerations. Oral sustained release formulations: design and evaluation. New York: Pergamon; 1988. p. 182.

40. Bettini R, Catellani P, Santi P, Massimo G, Peppas N, Colombo P. Translocation of drug particles in HPMC matrix gel layer: effect of drug solubility and influence on release rate. J Control Release. 2001;70(3):383-91.

41. Peppas NA. Analysis of Fickian and non-Fickian drug release from polymers. Pharm Acta Helv. 1985;60(4):110-1.

42. Ritger P, Peppas N. A simple equation for description of solute release. II: Fickian and anomalous release from swellable devices. J Control Release. 1987;5(1):37-42.

43. Ritger P, Peppas N. A simple equation for description of solute release. I: Fickian and non-Fickian release from non-swellable devices in the form of slabs, spheres, cylinders or discs. J Control Release. 1987;5(1):23-36.

44. Rowe RC SP, Owen SC. Handbook of pharmaceutical excipient. London: Pharmaceutical Press; 2006.

45. Ravi PR, Kotreka UK, Saha RN. Controlled release matrix tablets of zidovudine: effect of formulation variables on the in vitro drug release kinetics. AAPS PharmSciTech. 2008;9 (1):302-13. 
46. Rekhi GS, Nellore RV, Hussain AS, Tillman LG, Malinowski HJ, Augsburger LL. Identification of critical formulation and processing variables for metoprolol tartrate extended-release (ER) matrix tablets. J Control Release. 1999;59(3):327-42.

47. Perez-Marcos B, Ford JL, Armstrong DJ, Elliott PN, Rostron $\mathrm{C}$, Hogan JE. Influence of $\mathrm{pH}$ on the release of propranolol hydrochloride from matrices containing hydroxypropylmethyl- cellulose K4M and carbopol 974. J Pharm Sci. 1996;85 (3):330-4.

48. Fukui A, Fujii R, Yonezawa Y, Sunada H. Analysis of the release process of phenylpropanolamine hydrochloride from ethylcellulose matrix granules III. Effects of the dissolution condition on the release process. Chem Pharm Bull. 2006;54 (8):1091-6. 